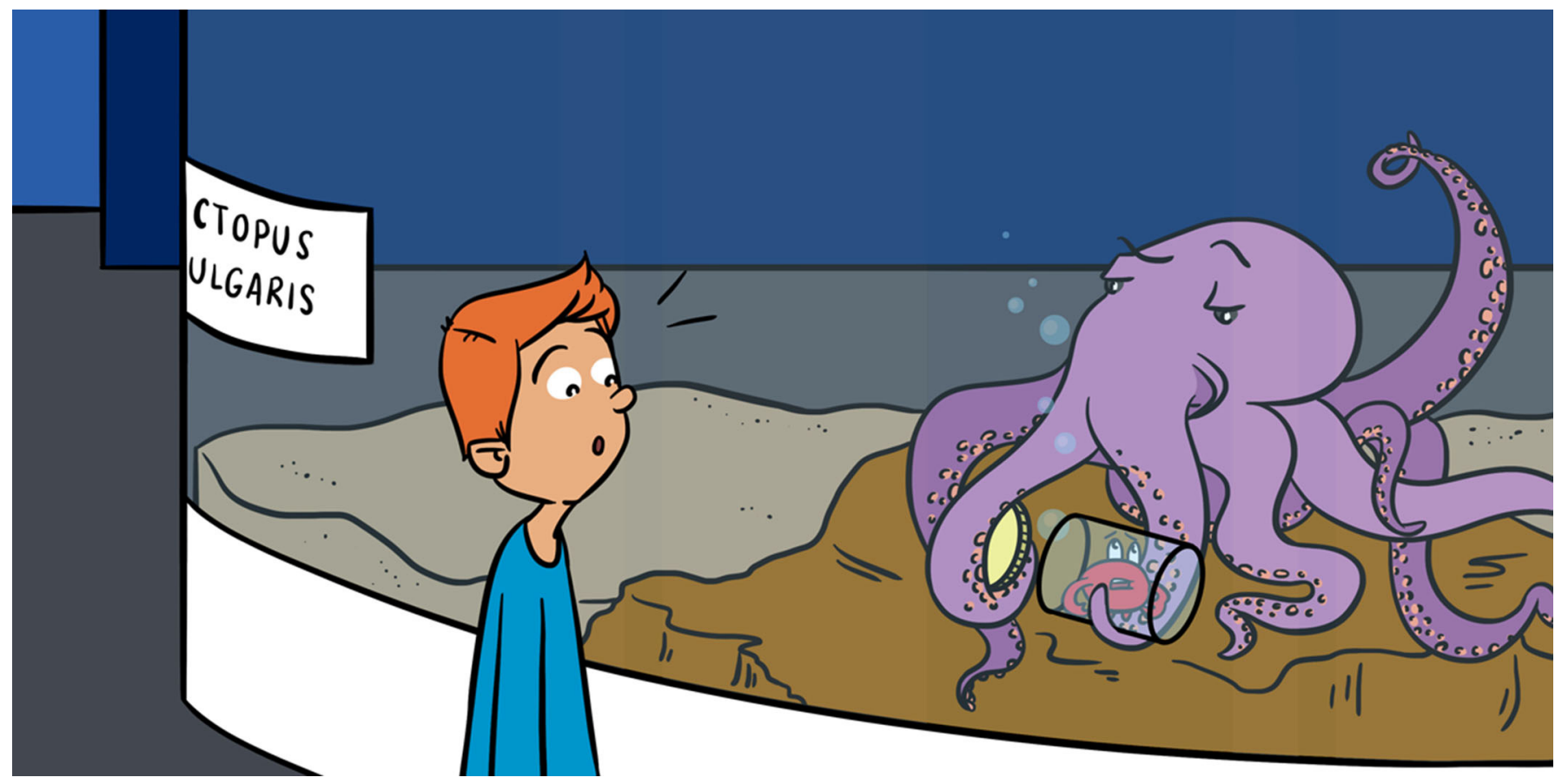

\title{
HOW DOES THE OCTOPUS EFFICIENTLY CONTROL ITS FLEXIBLE, MULTI-ARMED BODY?
}

\section{Nir Nesher* and Tal Shomrat}

Faculty of Marine Sciences, Ruppin Academic Center, Mikhmoret, Israel

YOUNG REVIEWERS:

EXCELLENCE PROGRAM, BRENNER

HIGH SCHOOL AGES: $13-14$

\section{MOTOR SKILLS}

Motor skills are actions that involve the movement of muscles in the body. A skilled movement can be defined as a movement that combine four different elements: force, velocity, accuracy, and purposefulness
The eight flexible arms of an octopus's body allow it to perform a wide range of actions. Octopi use their arms to perform several types of movement, such as walking, crawling, and swimming. They use different objects, such as empty coconut and clam shells, to create shelters, and they have the amazing ability to change their skin color and body texture to camouflage themselves in their environments. Simultaneously, the flexible body structure of the octopus creates a problem for its motor control system, because it needs to control and manage a nearly infinite number of body states. In this article, we will the interesting mechanisms octopi have developed to allow control over their unique bodies.

\section{THE OCTOPUS-NEARLY INFINITE MOVEMENT POSSIBILITIES}

Octopi are predator animals that live in caves and niches between rocks. Octopi exhibit complex behaviors, are extremely intelligent, and have high motor skills. In this case, "motor" means motion and movement, and octopi have several complex movement patterns, 
Figure 1

Octopus vulgaris. (1) Location of the brain (2) eyes, (3) arms, (4) suckers, and (5) the mouth, which is located where the arms converge on the body. Notice the great flexibility and various positions of the arms

\section{SIPHON}

A pipe- or funnel-like structure that is used by some marine animals for breathing. The octopus utilizes the siphon for other purposes like squirt water, cleaning their environments and for movement.

\section{SUCKERS}

Attachment structures on octopus arms, which help the animal to grab objects and perform other actions. The octopus has up to 2,000 suckers.

\section{VIDEO 1}

Octopus vulgaris solves a novel problem. It opens a screwed lid of a bottle to gain a piece of fish.

\section{MOTOR CONTROL} SYSTEM

The motor control system is the part of the nervous system that is controlled motor functions (i.e. movement).

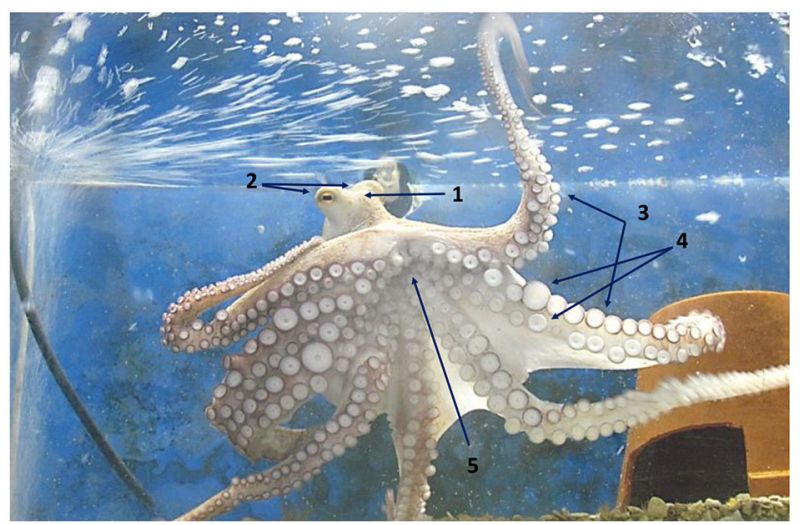

Figure 1

such as walking, crawling, and climbing. They swim using their arms; and to move away from danger zones, they squirt a strong jet of water, sometimes mixed with ink, from their siphon. The ink can cloud the vision of their predators and scare them away. Octopi use objects like empty coconut and clam shells to build shelters, and they have a wondrous ability to change their skin color and body texture to camouflage themselves in their environments.

Octopi consist primarily of soft, flexible tissue. The eight arms are flexible and have about 300 suckers each, as well as millions of sense receptors, mainly at the rims of the suckers, that can sense texture and taste (Figure 1). An octopus tastes its environment and the objects it encounters using the suckers on its arms. The combination of flexible arms and suckers allows it to efficiently catch and check out any object in its environment. An octopus uses its arms to catch food and bring the food to its mouth, to open clams, to catch animals hiding among or beneath corals and stones, and for various types of movement.

In the lab, using their arms, octopi have managed to remove the heavy covers of their aquaria and escape; open the lid of a jar to pick out a crab (Video 1), or reach into curved mazes to pull out a piece of food. The variety of complex actions that octopi perform using their arms requires a well-developed motor control system. The motor control system role is to initiate, direct, and grade purposeful voluntary movement. In order to effectively perform appropriate movements for the purposes they need to meet (such as catching prey, bringing food into the mouth, movement) the motor control system of an octopus must efficiently process enormous amounts of sensory information coming from hundreds of millions of sense receptors on the octopus body-and it must learn from all that information and remember experiences.

\section{HOW IS BODY MOVEMENT CONTROLLED IN HUMANS?}

Controlling a body with eight flexible arms is a great challenge for the motor control system. The stiff, bony skeletons that have developed 
PROPRIOCEPTIVE

SENSATION

The ability of the brain to sense the position of various body parts, even when the animal cannot see them.

\section{OPTICAL LOBES}

The optic lobes provide a system for coding the visual input, for storing a record of it and for decoding to produce particular motor responses [1].

PERIPHERAL NERVOUS SYSTEM (PNS)

The part of the nervous system that is outside the central nervous system (in humans, outside the brain and spinal cord).

\section{MOTOR PROGRAM}

A series of commands that result in a specific action, like the graduated stiffening of the arm muscles in "reaching movement" (stretching the arm toward a specific object usually to catch it).

STEREOTYPICAL MOVEMENT

A movement performed in the same typical manner every time.

VIDEO 2

Octopus vulgaris performs a reaching movement by bend propagation toward a piece of fish. It then brings it to its mouth by modifying its arm to a human-like limb in order to control precise point-to-point arm movements. in humans and many other animals limit the number of possible movements, but skeletons also decrease the number of possible body positions, which makes motor control much easier. Let us take the human arm, for example. We have both an upper arm and a forearm (lower arm), both of which contain bones and therefore cannot really change their shapes. Between the bones of the upper arm and forearm there is one joint-the elbow. The elbow joint allows the forearm to move at only one point compared to the upper arm. This movement is fairly limited: if the shoulder does not move, the forearm can move only up or down. Even if we consider the more complex finger joints of the hand, the number of different postures we can create with our hands is very small compared to the number of different possible postures an octopus can create with its completely flexible arms-and it has eight of them!

The reason for an octopus's flexibility is that there is no stiff skeleton in its arms, meaning that each segment along the whole arm can bend, twist, and even change its length and thickness. Therefore, the number of possible arm postures and body positions that the motor control system must keep track of in such a flexible body is nearly infinite. The limited number of postures of the human body allows the brain to directly control and monitor the position of each part of the body at every moment. This is why we can perform many actions without seeing our bodies, such as clapping our hands behind our backs: the brain simply knows where the limbs are without seeing them, which is called proprioceptive sensation. Constantly monitoring the positions of all body parts is not practical for the octopus, since such a large number of body positions cannot be represented in the brain.

\section{HOW DOES THE OCTOPUS CONTROL ITS BODY?}

The octopus has a relatively large nervous system, containing about half a billion nerve cells, similar to the nervous system of a rabbit. The system has three main centers: a central brain; two optical lobes to deal with information coming from the eyes, and the peripheral nervous system of the arms, containing two-thirds of all the nerve cells in the octopus's body. A relatively small number of nerve cells connects these three centers. The structure of the octopus nervous system tells us that most of the arm movements are controlled at the level of the arms. We think that the octopus's brain mostly serves to activate the motor programs that are already present in the arms [2].

If an arm is amputated from an octopus, that arm keeps living for a few hours, withdrawing from painful stimuli (like a pinch), and performing stereotypical movements like arm extension (Figure 2 and Video 2). Using the suckers, the amputated arm can transport food or an object toward the base of the arm, as if bringing it toward the mouth, or away from the base, as if moving it away from the 
Figure 2

Typical arm movements of Octopus vulgaris. In the top panel, from left to right, you can see several stages of arm extension, as the octopus reaches out for an object (matches figure in [3]). In the bottom panel, you can see the stages of a typical fetching movement, in which the octopus draws an object toward its body (matches figure in [4]).

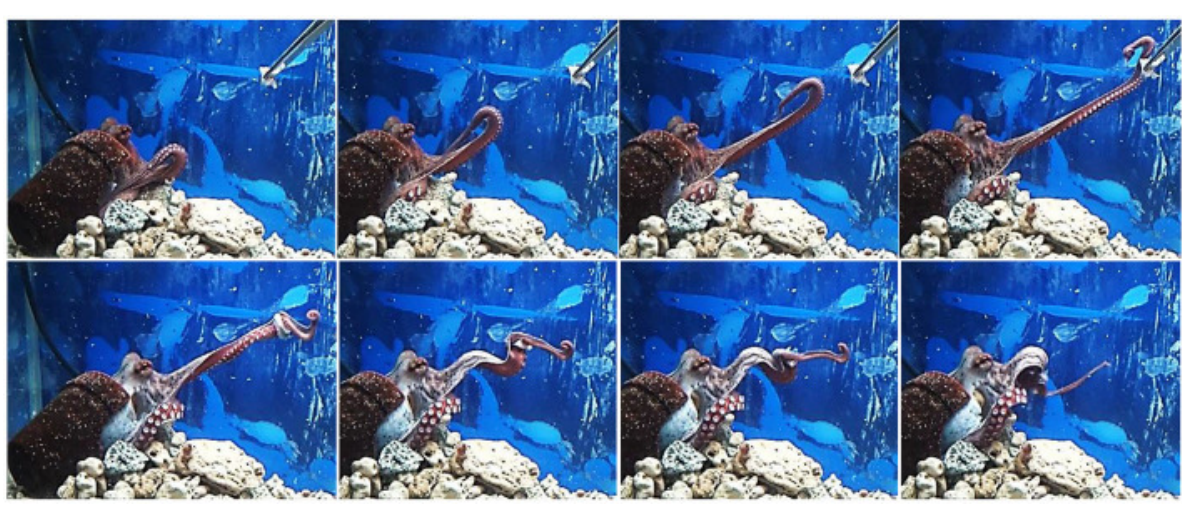

Figure 2

mouth. The amputated arm can even decide how strongly to hold onto different objects. For example, the arm will catch fresh fish more forcefully than it will a cooked crab [5]. This tells us that many routine actions, like extending and contracting the arm, are controlled at the level of the arm itself, reducing the brain's work a great deal. This mechanism is a clear advantage in an animal like the octopus, whose flexible and multi-limbed body structure would create a very heavy load for the brain.

\section{MOTOR PROGRAMS ARE ALREADY PRESENT IN THE OCTOPUS ARMS}

One command from the brain triggers muscle contraction events that progresses along the arm and causes it to stiffen and stretch from base to tip (reaching for food for example, see Figure 2). Research has shown that the brain only needs to control the speed of arm extension and the angle of the arm base with respect to the body, which determines the direction of arm movement [3]. This motor program that embedded in the arm delegating control to the arm and decreases computational load from the brain.

A successful extension movement which led to catching a prey requires a sequential movement of bringing the prey to the mouth. It is important to note that each point along the arm can be the point where they prey is caught. A research lead by Sumbre et al. [4] showed, as presented in Figure 2 and Video 2 that the octopus usually uses a stereotypical movement which divides the arms section from base to prey into three segments: proximal (close to the base of the arm); medial (middle) and distal (far from the base of the arm). The distal segment catches the object and is used as a hand, while in the proximal and medial segments muscles are contracted for creating two stiff segments, similar in length, with a flexible area simulating a joint between them. This design is similar to a human arm, divided by joints to an upper arm, a forearm, and a hand. To brings the food to its mouth the octopus bending the medial flexible area ("parallel 
to an elbow"), a stereotypical movement that combine only three controllable parameters.

It is important to note that, in contrast to the humans arm the octopus arm can re-determine the division of the arm and location of joints in each movement. That is how the octopus "kills two birds with one stone": it decreases a few computational factors, but maintains the flexibility and efficiency allowing it to catch an object in each point along the arm, and not only in the hand, as in humans.

\section{WHY DOES NOT AN OCTOPUS "CATCH" ITSELF?}

As mentioned, each of an octopus's arms is equipped with 300 suckers along its length. The suckers tend to attach to almost everything they contact. Why do not these flexible arms touch other parts of the octopus's body and "catch" them? This problem is compounded by the fact that octopi seem to lack proprioceptive sensation, meaning they are not aware of the positions of their arms when they cannot see them.

In the lab, we found that the suckers of an octopus amputated arm never catch an object covered in octopus skin. We even found a substance in octopus skin that inhibits the attachment action of the suckers. This inhibition seems to be controlled by the individual suckers, since adjacent suckers will behave differently if only one of them touches octopus skin. The brain can cancel this mechanism in unique cases, such as during a fight with another octopus or during mating. Control of this mechanism at the level of the suckers is another efficient strategy to reduce the work of the brain, and allow the octopus to control its flexible and "sticky" arms, even when it cannot see them.

\section{SUMMARY}

The flexible, multi-armed body structure of the octopus allows it to perform varied and complex behaviors but presents a big challenge for its motor control system. To deal with the challenge, a unique motor control system has developed in the octopus. Motor control in the octopus occurs not just at the level of the brain, but also at the level of each arm and even at the level of individual suckers. This vastly simplifies the work of the brain and allows octopi to be extremely flexible and move in ways that help them to solve complex problems. As octopi researchers, we believe that other unique and fascinating mechanisms are still waiting to be discovered!

\section{REFERENCES}

1. Young, J. Z. 1962. The optic lobes of Octopus vulgaris. Phil. Trans. R. Soc. Lond. B. 245:19-58. doi: 10.1098/rstb.1962.0005 
2. Levy, G., and Hochner, B. 2017. Embodied organization of Octopus vulgaris morphology, vision, and locomotion. Front. Physiol. 8:164. doi: 10.3389/ fphys.2017.00164

3. Gutfreund, Y., Flash, T., Yarom, Y., Fiorito, G., Segev, I., and Hochner, B. 1996. Organization of octopus arm movements: a model system for studying the control of flexible arms. J. Neurosci. 16:7297-307. doi: 10.1523/JNEUROSCI. 16-22-07297.1996

4. Sumbre, G., Fiorito, G., Flash, T., and Hochner, B. 2006. Octopuses use a human-like strategy to control precise point-to-point arm movements. Curr. Biol. 16:767-72. doi: 10.1016/j.cub.2006.02.069

5. Nesher, N., Levy, G., Grasso, F. W., and Hochner, B. 2014. Self-recognition mechanism between skin and suckers prevents octopus arms from interfering with each other. Curr. Biol. 24:1271-5. doi: 10.1016/j.cub.2014.04.024

SUBMITTED: 03 August 2021; ACCEPTED: 08 October 2021; PUBLISHED ONLINE: 03 November 2021.

EDITED BY: Idan Segev, Hebrew University of Jerusalem, Israel

CITATION: Nesher N and Shomrat T (2021) How Does the Octopus Efficiently Control Its Flexible, Multi-Armed Body? Front. Young Minds 9:752728. doi: 10.3389/ frym.2021.752728

CONFLICT OF INTEREST: The authors declare that the research was conducted in the absence of any commercial or financial relationships that could be construed as a potential conflict of interest.

COPYRIGHT @ 2021 Nesher and Shomrat. This is an open-access article distributed under the terms of the Creative Commons Attribution License (CC BY). The use, distribution or reproduction in other forums is permitted, provided the original author(s) and the copyright owner(s) are credited and that the original publication in this journal is cited, in accordance with accepted academic practice. No use, distribution or reproduction is permitted which does not comply with these terms.

\section{YOUNG REVIEWERS}

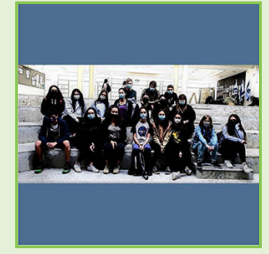

\section{EXCELLENCE PROGRAM, BRENNER HIGH SCHOOL, AGES: 13-14}

Students of the excellence program (7th and 8th grades) of the Brenner High School, Givat Brenner, from "Bet Or" and "Bereshit" schools.

\section{AUTHORS}

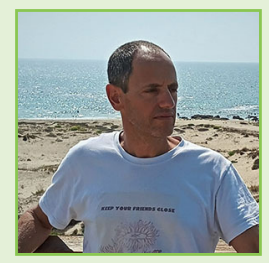

\section{NIR NESHER}

I was raised in Kibbutz Beit Zera. When I was younger, I spent most of my time in nature and doing agricultural work. After the army, I traveled the world for almost 10 years, and it sparked my strong interest in topics related to marine sciences and the Earth. When I came back, I studied marine sciences. Now I have a Ph.D. in that field and I am a senior lecturer at the Faculty of Marine Sciences 


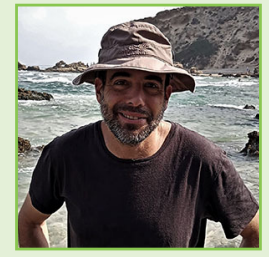

at the Rupin Academic Center. In our lab, Dr. Shomrat and I study the octopus, one of the most interesting animals in nature. We focus on behavior, memory, learning and the unique motor control system that developed in this flexible, multi-armed creature. *nir.nesheramail.huji.ac.il

\section{TAL SHOMRAT}

I am a researcher at the Faculty of Marine Sciences at Ruppin Academic Center. In a lab on the coast of the Mediterranean Sea, I grow octopi, cuttlefish, and flat worms called planarians. Using behavioral tests and observing the brain activity of these three animals, I try to understand the basis of complex behavior, learning, and memory. I have been diving since a very young age, and I became acquainted with the octopus in my childhood, much before I knew that one day I would be a doctor, studying these wondrous creatures. 